\title{
An Overview of Thematic Evolution of Physical Therapy Research Area From 1951 to 2013
}

\author{
Jose A. Moral-Munoz ${ }^{1,2 *}$, Manuel Arroyo-Morales ${ }^{3}$, Enrique Herrera-Viedma ${ }^{4}$ \\ and Manuel J. Cobo ${ }^{5}$
}

'Department of Nursing and Physiotherapy, University of Cádiz, Cádiz, Spain, ${ }^{2}$ Institute of Research and Innovation in Biomedical Sciences of the Province of Cadiz (INiBICA), University of Cádiz, Cádiz, Spain, ${ }^{3}$ Instituto Mixto Deporte y Salud (iMUDS), University of Granada, Granada, Spain, ${ }^{4}$ Department of Computer Science and Artificial Intelligence, CITIC-UGR (Research Center on Information and Communications Technology), University of Granada, Granada, Spain, ${ }^{5}$ Department of Computer Science and Engineering, University of Cádiz, Cádiz, Spain

OPEN ACCESS

Edited by:

Zaida Chinchilla-Rodríguez, Consejo Superior de Investigaciones

Cientificas (CSIC), Spain

Reviewed by: Jiangen $\mathrm{He}$,

Drexel University, United States Carlos Olmeda-Gómez, Universidad Carlos III de Madrid,

Spain

*Correspondence:

Jose A. Moral-Munoz joseantonio.mora/@uca.es

Received: 18 December 2017 Accepted: 28 February 2018

Published: 21 March 2018

Citation:

Moral-Munoz JA, Arroyo-Morales M, Herrera-Viedma E and Cobo MJ (2018) An Overview of Thematic

Evolution of Physical Therapy Research Area From 1951 to 2013.

Front. Res. Metr. Anal. 3:13. doi: 10.3389/frma.2018.00013
Physical Therapy is a profession which development and conceptual framework have been performed in the twentieth century. One of the major challenges of Physical Therapy in the twenty-first century is to identify the intellectual basis of its scientific domain. The aim of the present paper is to analyze the evolution of Physical Therapy research throughout scientific literature published in Web of Science (WoS) and Scopus databases. In order to perform the analysis, WoS and Scopus bibliographic databases were used to download all records. A set of journals with overall topics in Physical Therapy discipline with the largest history in the Journal Citation Report were selected: Physiotherapy, Physical Therapy, and Australian Journal of Physiotherapy/Journal of Physiotherapy. The bibliometric tool SciMAT was employed to perform a science mapping analysis in order to detect and visualize the research themes and their evolution across three periods: 1951-1984, 1985-2000, and 2001-2013. The analysis carried out shows that Physical Therapy research field is mainly divided into nine thematic areas: Middle-Aged People, Muscle Function Alterations and Recovery, Health Education, Gait and Biomechanics, Central Nervous System, Heart Rate and Exercise, Diagnosis, Low Back Pain, and Animals. In conclusion, Physical Therapy citations and production are primarily focused on two large thematic areas, diseases that involve middle-aged population and muscle function and its alterations. Results can be used to provide a historical perspective on research conducted in this emerging field and to provide a scientific evidence-based practice model on which future studies can be built.

Keywords: physical therapy, bibliometrics, scientometrics, science mapping analysis, thematic evolution

\section{INTRODUCTION}

The development and conceptual framework of Physical Therapy have been produced in the twentieth century (Massey, 2001, 2003; French and Dowds, 2008). Its body of knowledge is continually growing and becoming more specific (García-Ríos et al., 2010). In relation to that knowledge, in the twenty-first century, Physical Therapy has a challenge to identify the intellectual basis of its scientific domain (Martínez-Fuentes et al., 2014). Furthermore, it would be interesting to see the evolution of Physical Therapy research over time and to know which themes are currently the most important and which can be the future trends. 
In this way, bibliometrics allows automatically classify studies over time into different themes and topics in order to facilitate the analysis of a research field (van Raan, 2005). It is commonly employed to quantify academic research output (van Leeuwen and Wouters, 2017), which is used for practice-based research (Gutiérrez-Salcedo et al., 2017). Particularly, Science Mapping Analysis (SMA) (Cobo et al., 2011b) is a potent bibliometric technique, which combined with bibliometric co-word networks, is able to identify the structure of a research field through the use of the most important terms or keywords that compound the documents (Callon et al., 1983).

Taking into account the scientific literature, several bibliometric studies about the impact of the Physical Therapy research field can be highlighted. First, Tilson et al. (2016) performed an analysis of the American Physical Therapy Association journals in order to discover the statistical terms used from 2011 to 2012. They concluded that 81 representative terms constituted the $90 \%$ of all concurrences (a total of 532 terms). Simon et al. (2014) analyzed the content and scientific trend of the articles published in the Journal of Manual \& Manipulative Therapy from 1993 to 2012. As conclusion, the research for adolescents, older adults, and for upper and lower extremity were considered as important for the future. Saragiotto et al. (2014) described the study designs employed in the Brazilian Physical Therapy production, addressing that most of the research used levels II and III of evidence. Martínez-Fuentes (2014) and Martínez-Fuentes et al. (2014) treated to characterize the intellectual basis of the Physical Therapy area through a co-citation analysis in three international impact journals (Physical Therapy, Physiotherapy, and Australian Journal of Physiotherapy). They stated that the Physical Therapy area is a young discipline with an interest on the evidence-based practice. Wiles et al. (2012) analyzed the research production in Physical Therapy Journal from 1945 to 2010. The study led to the conclusion that the production comprising high-quality research from large research concentrations from different countries and affiliations. Coronado et al. (2011) conducted a bibliometric analysis of the articles published from 1980 to 2009 in Physical Therapy Journal. They stated that there was an increment in the interest on articles focused on evidence-based practice and clinically based research. Vernaza-Pinzón and Álvarez-Bravo (2011) characterized the Physical Therapy scientific literature output in Latin America from 2000 to 2007, concluding that Brazil is the country with the higher production and it was centered on the community-based rehabilitation. Lastly, Wakiji (1997) performed a study where Physical Therapy literature was mapped analyzing the articles' cited references in Physical Therapy Journal and Archives of Physical Medicine and Rehabilitation. The high citation from journals of the Physical Therapy (representing the 77\% of the cites) area was highlighted. In views of this background, the present study adds new knowledge about the impact and evolution of the Physical Therapy research.

Therefore, the main aim of this analysis is to describe the scientific evolution of Physical Therapy research through articles published in Physiotherapy, Physical Therapy Journal, and Journal of Physiotherapy/Australian Journal of Physiotherapy from 1951 to 2013. This paper describes how a longitudinal SMA was undertaken to identify this emerging field of research, its structure, its conceptual evolution over time, and the future research directions.

\section{MATERIALS AND METHODS}

\section{Data Extraction}

In order to carry out the analysis, Web of Science (WoS) and Scopus databases were used to retrieve the documents indexed in the three classics journals that compose the Physical Therapy core scientific publications in Rehabilitation category: Physiotherapy, Physical Therapy Journal, and Australian Journal of Physiotherapy/Journal of Physiotherapy. The last two journals could be considered as one, since the title changed in 2010 from Australian Journal of Physiotherapy to Journal of Physiotherapy. These journals were selected because they are those with a higher number of years indexed in WoS Rehabilitation category and focused on the general knowledge domain, covering the professional development of this discipline and with a higher number of documents. Furthermore, this approach was previously applied in research (Martínez-Fuentes, 2014; Martínez-Fuentes et al., 2014).

Web of Science and Scopus were used together in order to obtain the whole production, Physiotherapy (Scopus: 1986-2004; WoS: 2005-2013), Physical Therapy Journal (WoS: 1964-2013), and Journal of Physiotherapy/Australian Journal of Physical Therapy (Scopus: 1973-2008; WoS: 2009-2013). An amount of 8,146 documents (articles and reviews) was downloaded from 1951 to 2013 (WoS: 6,700; Scopus: 1,446). The citations retrieved count up to May 2014. The authors' keywords and keywords plus from WoS and authors' keywords and index keywords from Scopus were jointly used to build the different diagrams and networks.

\section{Data Analysis}

Through the analysis, SMA (Cobo et al., 2011b) highlights the relation among disciplines, fields, specialties, and individual documents or authors into the research production by means of spatial representation (Small, 1999; Chinchilla-Rodríguez et al., 2016). It monitors a research field and determines the structure and evolution of the discovered research areas, displaying its conceptual, intellectual, and social aspects (Noyons et al., 1999; Börner et al., 2003; Morris and Van Der Veer Martens, 2008; Vargas-Quesada et al., 2017). The open-source software SciMAT is used to carry out the SMA analysis performed in the present article (Cobo et al., 2012).

Different bibliometric tools are available to perform this kind of study (Cobo et al., 2011b), but SciMAT contains some characteristics that distinguish it from other SMA software tools. SciMAT divides the analysis into four phases. A detailed explanation of the four phases can be found elsewhere (Cobo et al., 2012; Moral-Munoz et al., 2014), although a brief description is shown below:

1. Research themes detection: in this phase, the aim is to detect the research problems and/or centers of interest that are attracting the researchers' attention. A normalized co-word network using the keywords co-occurrence is built. After the 
network generation, the simple center algorithm (Coulter et al., 1998) is employed to define the themes of relevance in the research area.

2. Generation of the strategic diagrams. A two-dimensional strategic diagram is obtained by plotting each detected cluster (Callon et al., 1991). Once the research themes are mapped into a two-dimensional space, they can be classified into four groups (Cobo et al., 2011a): (1) Motor themes: appear in the upper-right quadrant and are considered well developed and important for the structuring of a research field. (2) Basic and transversal: appear in the lower-right quadrant and are considered important for a research field but are not yet developed. (3) Emerging or declining: appear in the lower-left quadrant and are considered weakly or marginally developed. (4) Highly developed and isolated: appear in the upper-left quadrant and are considered to be well developed but of marginal importance for the field.

3. Discovery of thematic areas. In order to discover the origins and interrelationships of the primary thematic areas, the evolution of the different research themes detected before is analyzed over a set of different periods. In the visualization, columns correspond to the different subperiods established to divide the whole time span. The spheres' volume is proportional to the number of documents associated with each theme. When both themes have the same name, or they share a part of the name, they are linked by solid lines. Furthermore, if the themes share elements but not the name, they are linked by a dotted line. The color-shadows group the themes that belong to the same thematic area. If a theme does not have a shadow, it means that it does not belong to any thematic area.

4. Performance analysis. In order to measure the relative contribution of the research themes and thematic areas quantitatively and qualitatively, some performance values can be added to these sets: number of published documents, number of received citations, and h-index (Hirsch, 2005; Alonso et al., 2009). Once the sets of documents are associated with each cluster [using a document mapper function (Cobo et al., 2011b)] and the performance values are added, the most prominent, productive, and highest-impact subfields may be identified.

Before performing the analysis mentioned above, document's keywords were submitted to different pre-processing tasks: (i) a de-duplicating process was applied to group the synonymous, such as the plural and singular forms, in order to identify a single word representing a concept; (ii) furthermore, descriptive keywords were manually added to ensure completeness, because several documents did not contain any keywords; and (iii) finally, meaningless keywords in this conceptual framework, such as stop words, or words with general or wide meanings, were removed (e.g., outcomes, disease, system, and so on). In Figure 1, the workflow of the SMA performed is shown.

In order to establish the number of periods to analyze, two, three, and four subperiods were tested. Finally, three subperiods were established during the whole period (1951-2013), because using two subperiods, no evolution was analyzed; and with four subperiods, there were not enough document count to obtain an

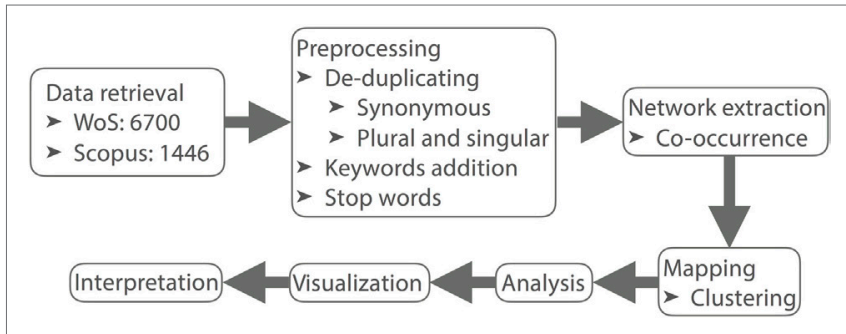

FIGURE 1 | Workflow of the analysis performed.

appropriate analysis. Likewise, it is common to use subperiods of the same number of years, but in the first years, the number of researchers and publications were low (Figure 2). Therefore, the documents were grouped inequality to obtain an adequate number of documents in each defined subperiod, in order to have enough keywords to perform the analysis previously described. Then, a first subperiod of 34 years (1951-1984), a second subperiod of 16 years (1985-2000), and a third subperiod of 13 years (2001-2013) were established.

\section{RESULTS}

Once the analysis was performed, some results were obtained about the different themes detected and the thematic evolution of the Physical Therapy field.

\section{Visualization of Themes}

A strategic diagram was built using SciMAT, in order to analyze the most notable themes for each subperiod. In these spatial representations (Figures 3-5), the spheres' volume is proportional to the number of documents associated with each theme. In brackets, the number of citations associated with each theme is also depicted. On the other hand, different tables (Tables 1-3), with information about the performance values (number of documents, h-index, and number of citations), are addressed in order to provide an overview of the themes' impact. Furthermore, the information about the main documents that compose the themes is used to make some observations.

\section{Period 1951-1984}

Relating to the strategic diagrams shown in Figure 3 and bibliometric indicators in Table 1, some results are remarkable.

The motor themes of Central Nervous System and Education and the emerging/declining theme Psychological Aspect present similar high publications values, considered as highlighted themes. The theme Central Nervous System is focused on child psychomotor development and alterations derived from the cerebrovascular accident (Duncan et al., 1983; Holden et al., 1984). The theme Education, although with a high number of publications, has a low h-index. It is a broad theme that involves issues concerning academic aspects to conform the Physical Therapy curricula (Emery, 1984). The theme Psychological Aspect is composed of articles related to different variables that could influence health problems (e.g., geographic distribution, economic aspect, and so on) (Short et al., 1984). 


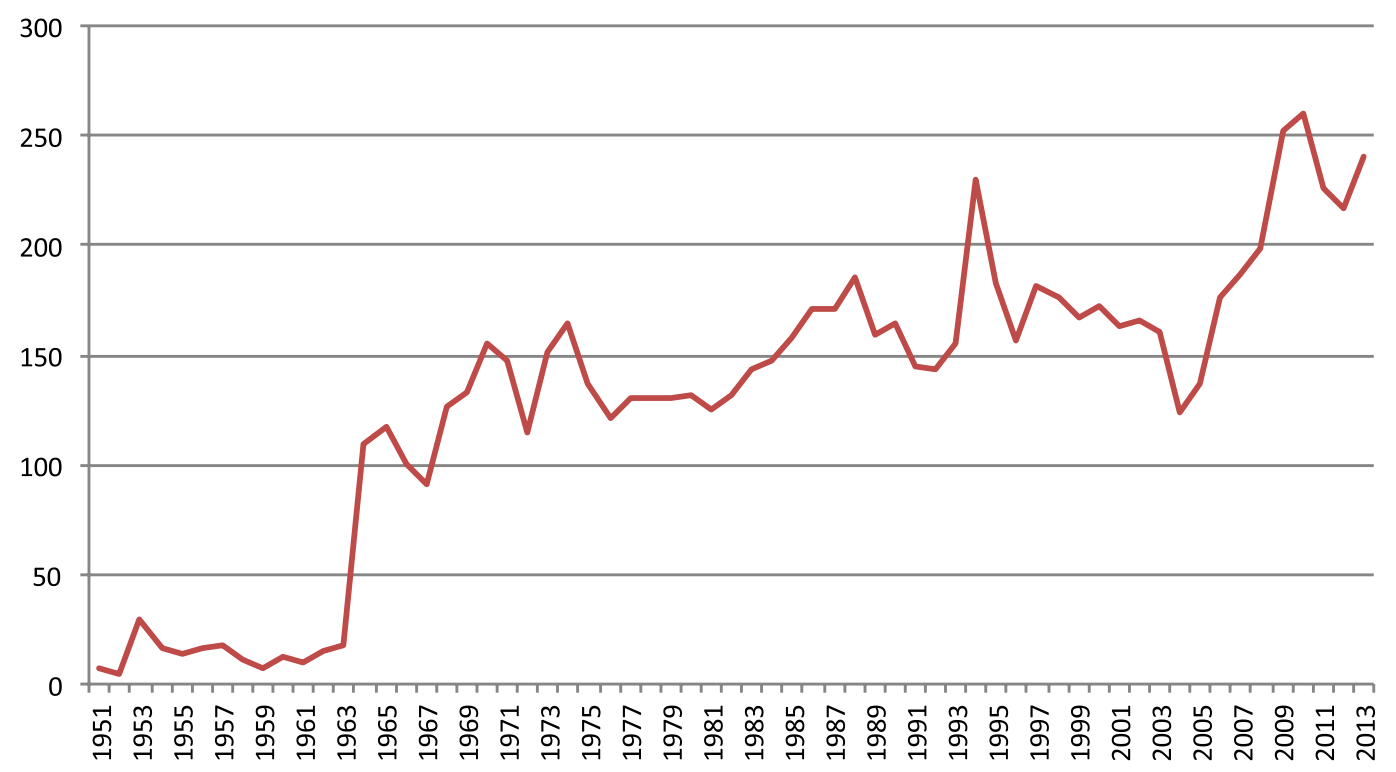

FIGURE 2 | Evolution of the Physical Therapy production from 1951 to 2013.

The basic and transversal themes Diagnosis, Knee, and Gait along with the motor theme Muscle Contraction obtain the best performance results with the highest h-index and citations count. The theme Diagnosis is composed of documents that enhance the importance of the physical therapy diagnosis (Boone et al., 1978). The theme Knee is related to diseases, treatments, and disability assessment of the knee joint (Gajdosik and Lusin, 1983; Rothstein et al., 1983). Another main theme, Gait, is related to movement disorders and orthopedic equipment, being important in relation to posture and locomotion assessment (Holden et al., 1984). Finally, the theme Muscle Contraction even has better performance values than Knee and Gait with less number of documents. It is mainly related to muscle physiology and biomechanics (Murray et al., 1980).

Finally, it is interesting to highlight the isolated and highly developed theme Animal and the motor theme Heart. The theme Animal has low-performance values, but it is the origin of a thematic area in Physical Therapy research focused on animal experimentation (Gossman et al., 1982). Otherwise, the theme Heart has moderate performance values, but it is the beginning of a thematic area in the whole period. It is related to the rehabilitation of conditions of the cardiovascular system (Dull and Dull, 1983).

\section{Period 1985-2000}

According to the strategic diagrams (Figure 4) and bibliometric indicators (Table 2), some observations should be remarked.

The motor theme Middle Aged presents the highest performance values. It has more than double of citations respect to theme Gait, ranked second in number of citations and h-index. This theme is wide and is related to different middle-aged population health aspects, such as activities of daily living (Jevsevar et al., 1993), cerebrovascular accident (Malouin et al., 1992), or time factors (Lord and Castell, 1994). As mentioned above, it is remarkable the motor theme Gait with the second better performance values but with less number of documents than Education or Diagnosis. This theme is related to anatomical body parts involved in gait, walking aids, biomechanics, and gait disorders.

The motor theme Education has a high number of documents published with the second place in number of documents, but its scientific impact seems to be low. There are also three remarkable themes, the basic or transversal themes Diagnosis and Low Back Pain, and the motor theme Quadriceps Femoris Muscle; they present high impact values with half of the documents that Middle Aged or Education. According to the above, the theme Diagnosis has less strength and in the next period, it disappears. In this period, the theme Low Back Pain strongly appears becoming a cornerstone of a new thematic area. It is related to anatomical aspects, pain assessment, and treatments of this disease (Lindstrom et al., 1992). The theme Quadriceps Femoris Muscle is focused on different knee injuries and thigh muscles aspects (Winter et al., 1990); it is also remarkable the relationship with electric stimulation (Snyder-Mackler et al., 1994).

Besides, the themes Pain, Body Equilibrium, and Muscle Function obtain high performance values, especially in h-index. The theme Pain is related to different diseases and treatments and focused on the differences in pain thresholds among people (Hogeweg et al., 1996). Body Equilibrium is related to cerebral aspects involved in equilibrium and it is evident the importance in geriatric research (Shumway-Cook et al., 1997). The third theme worthy to mention, Muscle Function, is focused on biomechanical and physiological aspects of muscle activity (Bandy et al., 1997).

Finally, the isolated or highly developed theme Animal is present in this period but with low-performance values. It disappears in next period and it forms along with the first period a little thematic area. 


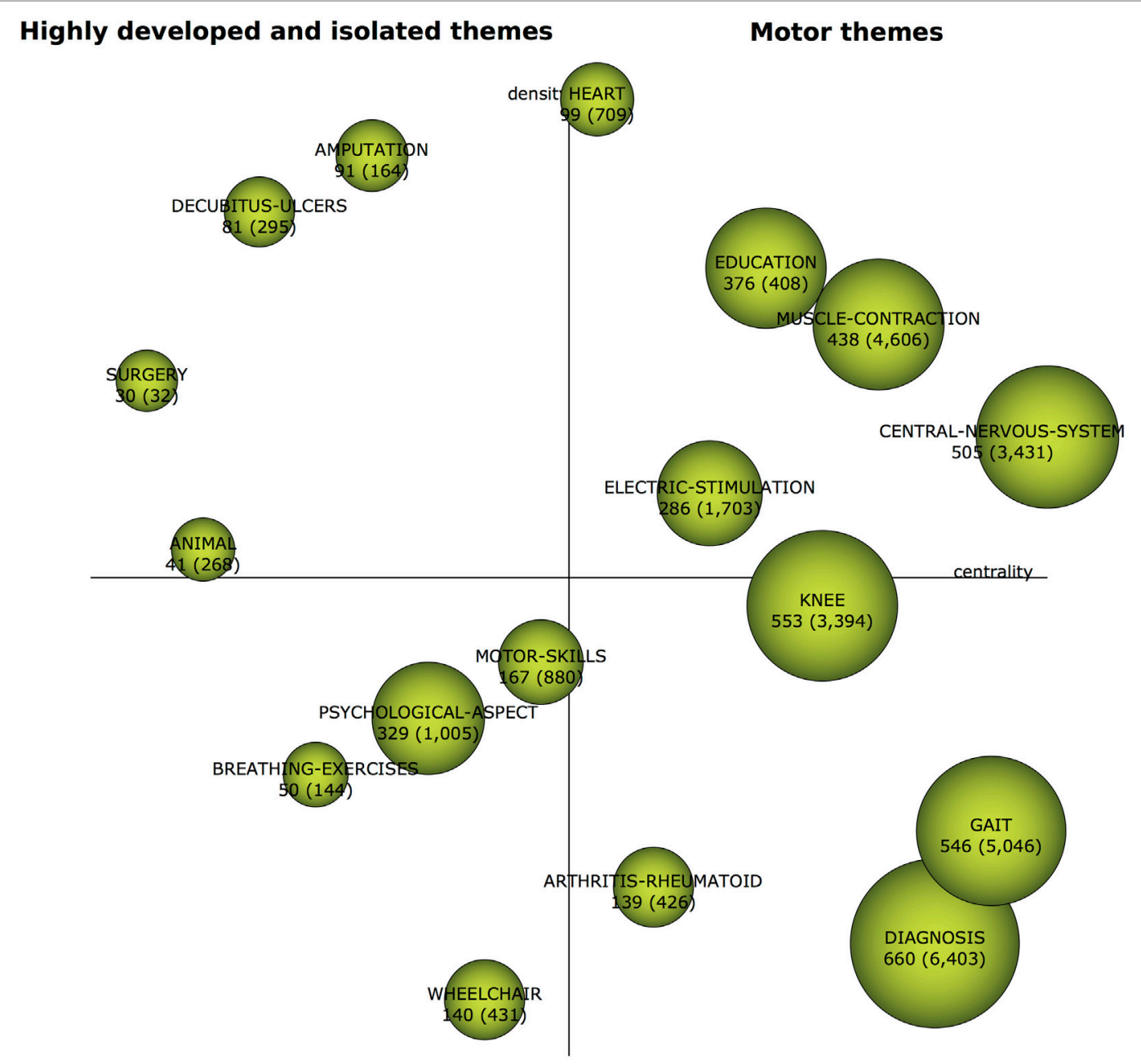

\section{Emerging or declining themes}

Basic and transversal themes

FIGURE 3 | Strategic diagram for the subperiod 1951-1984.

\section{Period 2001-2013}

According to the strategic diagrams (Figure 5) and bibliometric indicators (Table 3) obtained in this period, different findings should be remarked.

In this period, the motor theme Middle Aged is consolidated. It also presents the highest-impact values. The basic and transversal theme Follow Up and the motor theme Body Equilibrium also have very high and similar performance values. The theme Follow Up is related to research documents based on different health aspects that require time control [e.g., neck pain treatment (Cleland et al., 2007), quality of life (Chien et al., 2008), and so on]. Body Equilibrium gets a higher production in this period, becoming the third theme with better performance values.

Kinesiotherapy, Cerebrovascular Accident, Evidence-Based Practice, and Low Back Pain compose another group that also presents high performance values. The basic and transversal theme Kinesiotherapy is focused on musculoskeletal disorders and treatments (Smidt et al., 2005). Cerebrovascular Accident appears as an important motor theme and is mainly related to morbidities due to this disease (Blum and Korner-Bitensky, 2008). Otherwise, the theme Evidence-Based Practice appears as a signal about this Physical Therapy approach to clinical practice. Finally, it is interesting to highlight that theme Low Back Pain also appears in this period and seems to have a growing pattern.

The basic or transversal theme Education loses strength in this period, this fact could reflect that the Physical Therapy curricula is highly developed. According to previous studies (Coronado et al., 2011), the research in Physical Therapy education is high due to its development but in this period education aspects seem to be established. On the other hand, the isolated theme Exercise Test is related to different form of evaluation during exercise [e.g., oxygen consumption (Berney and Denehy, 2003), exercise tolerance (Folpp et al., 2006), and so on]. This theme has less importance in Physical Therapy research, but seems to be a clear research line related to exercise and cardiovascular aspects. 
TABLE 1 | Bibliometric indicators of period 1951-1984.

\begin{tabular}{lccc}
\hline Theme Name & $\begin{array}{c}\text { Number of } \\
\text { documents }\end{array}$ & H-index & $\begin{array}{r}\text { Number of } \\
\text { citations }\end{array}$ \\
\hline Diagnosis & 660 & 36 & 6,403 \\
Knee & 553 & 30 & 3,394 \\
Gait & 546 & 34 & 5,046 \\
Central Nervous System & 505 & 29 & 3,431 \\
Muscle Contraction & 438 & 34 & 4,606 \\
Education & 376 & 10 & 408 \\
Psychological Aspect & 329 & 16 & 1,005 \\
Electric Stimulation & 286 & 21 & 1,703 \\
Motor Skills & 167 & 14 & 880 \\
Wheelchair & 140 & 10 & 431 \\
Arthritis Rheumatoid & 139 & 11 & 426 \\
Heart & 99 & 16 & 709 \\
Amputation & 91 & 7 & 164 \\
Decubitus Ulcers & 81 & 11 & 295 \\
Breathing Exercises & 50 & 6 & 144 \\
Animal & 41 & 8 & 268 \\
Surgery & 30 & 2 & 32 \\
& & &
\end{tabular}

\section{Thematic Evolution Over Time}

In relation to the thematic evolution, nine thematic areas have been identified over these three subperiods: Middle-Aged People, Muscle Function Alterations and Recovery, Health Education, Gait and Equilibrium, Central Nervous System, Diagnosis, Low Back Pain, Heart Rate and Exercise, and Animal. Thus, to analyze the evolution of this field, Figure 6 and Table 4 show several findings that need to be remarked to note thematic relationships about composition, structure, and impact.

In line with the thematic composition of the research area, several findings should be pointed out: the thematic area MiddleAged People is composed of motor and emerging/declining themes. It includes the two last periods one important motor theme, called as this thematic area. Gait and Equilibrium starts with a basic theme focused in gait and it develops into a motor theme in last period, more related to equilibrium. It is mainly composed of basic and motor themes.

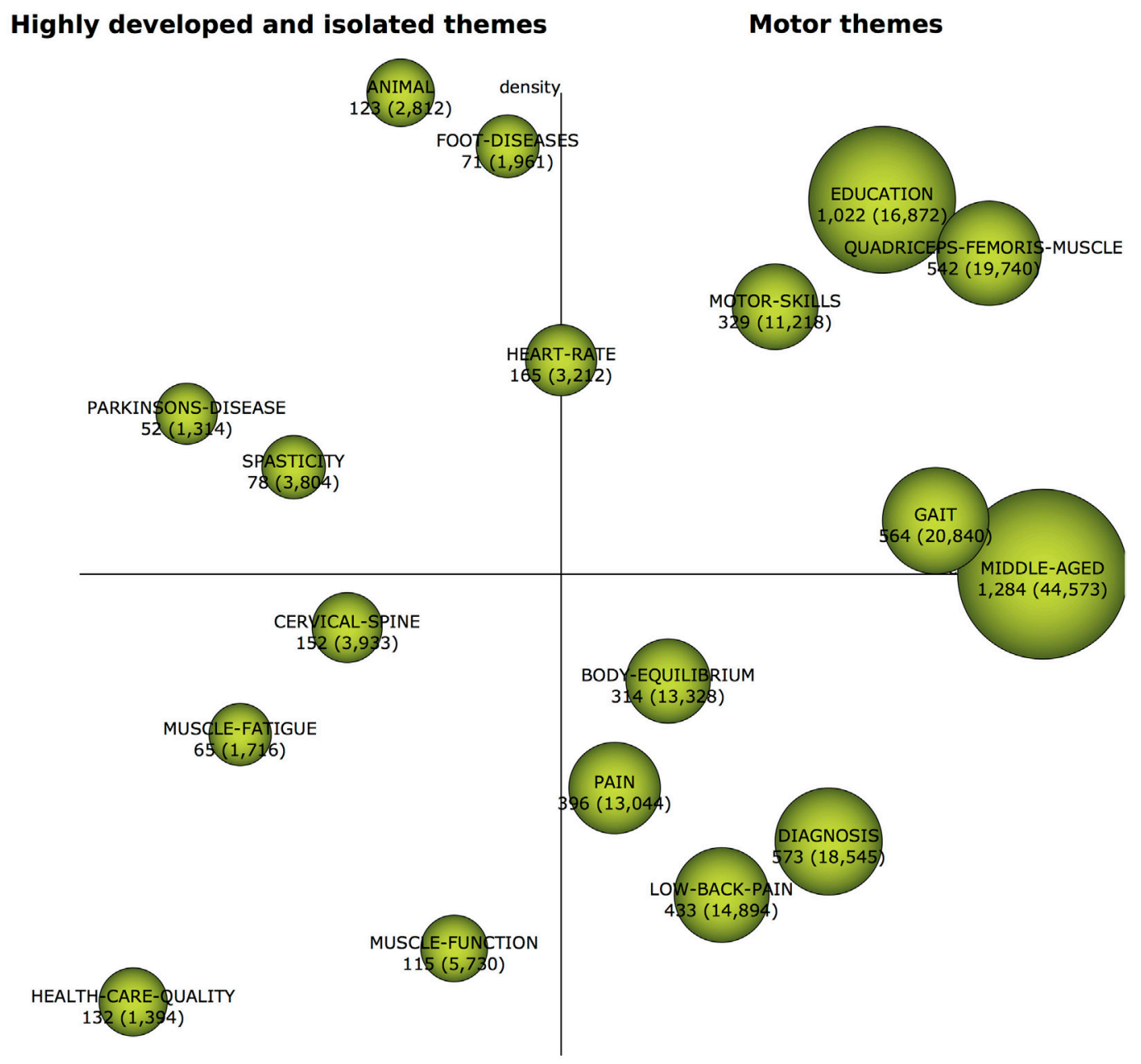

Emerging or declining themes

Basic and transversal themes 
TABLE 2 | Bibliometric indicators of period 1985-2000.

\begin{tabular}{lccc}
\hline Name & $\begin{array}{c}\text { Number of } \\
\text { documents }\end{array}$ & H-Index & $\begin{array}{c}\text { Number of } \\
\text { citations }\end{array}$ \\
\hline Middle Aged & 1,284 & 100 & 44,573 \\
Education & 1,022 & 59 & 16,872 \\
Diagnosis & 573 & 66 & 18,545 \\
Gait & 564 & 76 & 20,840 \\
Quadriceps Femoris Muscle & 542 & 67 & 19,740 \\
Low Back Pain & 433 & 65 & 14,894 \\
Pain & 396 & 63 & 13,044 \\
Motor Skills & 329 & 57 & 11,218 \\
Body Equilibrium & 314 & 61 & 13,328 \\
Heart Rate & 165 & 32 & 3,212 \\
Cervical Spine & 152 & 36 & 3,933 \\
Health-Care Quality & 132 & 21 & 1,394 \\
Animal & 123 & 29 & 2,812 \\
Muscle Function & 115 & 43 & 5,730 \\
Spasticity & 78 & 26 & 3,804 \\
Foot Diseases & 71 & 23 & 1,961 \\
Muscle Fatigue & 65 & 26 & 1,716 \\
Parkinson's Disease & 52 & 22 & 1,314 \\
& & &
\end{tabular}

The thematic area Muscle Function Alterations and Recovery is mainly composed of motor and basic themes and is the thematic area with higher number of themes. The theme Muscle Contraction seems to be the main motor theme. Health Education has the theme Educationasmotorthemealongwholetimespan. Thisthematicarea is composed of other emerging themes that accompany the main theme.

The thematic area Central Nervous System starts from a motor theme that names it and it develops into other motor themes that are in relation to this wide theme. Heart Rate and Exercise is composed of motor themes in first two periods, but in the last period, it develops into an isolated theme.

The thematic area Diagnosis is consolidated as a basic theme throughout the first two periods but it disappears in the last period. Low Back Pain seems to be an important thematic area in future research, it starts in the second period and is composed of basic and emerging themes. Lastly, the thematic area Animal is formed by two isolated themes.

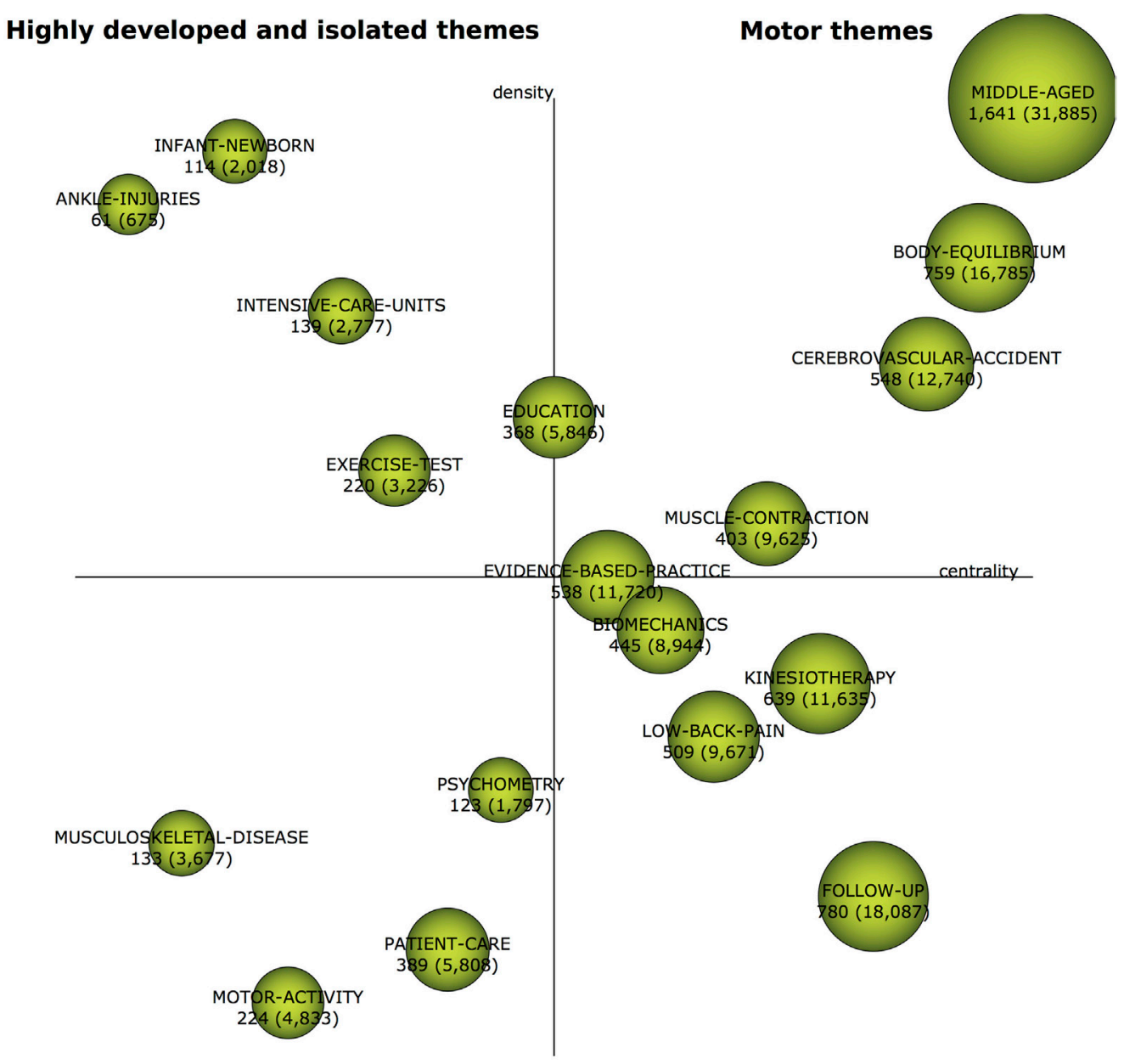

Emerging or declining themes

Basic and transversal themes 
TABLE 3 | Bibliometric indicators of period 2001-2013.

\begin{tabular}{lccc}
\hline Name & $\begin{array}{c}\text { Number of } \\
\text { documents }\end{array}$ & H-Index & $\begin{array}{c}\text { Number of } \\
\text { citations }\end{array}$ \\
\hline Middle Aged & 1,641 & 77 & 31,885 \\
Follow Up & 780 & 62 & 18,087 \\
Body Equilibrium & 759 & 61 & 16,785 \\
Kinesiotherapy & 639 & 54 & 11,635 \\
Cerebrovascular Accident & 548 & 57 & 12,740 \\
Evidence-Based Practice & 538 & 54 & 11,720 \\
Low Back Pain & 509 & 51 & 9,671 \\
Biomechanics & 445 & 49 & 8,944 \\
Muscle Contraction & 403 & 50 & 9,625 \\
Patient Care & 389 & 37 & 5,808 \\
Education & 368 & 36 & 5,846 \\
Motor Activity & 224 & 38 & 4,833 \\
Exercise Test & 220 & 27 & 3,226 \\
Intensive Care Units & 139 & 28 & 2,777 \\
Musculoskeletal Disease & 133 & 30 & 3,677 \\
Psychometry & 123 & 23 & 1,797 \\
Infant Newborn & 114 & 26 & 2,018 \\
Ankle Injuries & 61 & 15 & 675 \\
\hline
\end{tabular}

TABLE 4 | Performance values for the Physical Therapy thematic areas.

\begin{tabular}{lccc}
\hline Areas & $\begin{array}{c}\text { Number of } \\
\text { documents }\end{array}$ & H-Index & $\begin{array}{c}\text { Number of } \\
\text { citations }\end{array}$ \\
\hline Middle-Aged People & 3,150 & 113 & 78,071 \\
Muscle Function, Alterations, & 2,934 & 102 & 60,934 \\
and Recovery & 2,674 & 82 & 36,867 \\
Health Education & 2,259 & 99 & 53,098 \\
Gait and Equilibrium & 1,673 & 79 & 33,273 \\
Central Nervous System & 1,233 & 74 & 24,948 \\
Diagnosis & 1,121 & 81 & 28,860 \\
Low Back Pain & 484 & 40 & 7,147 \\
Heart Rate and Exercise & 164 & 30 & 3,080 \\
Animal & & & \\
\hline
\end{tabular}

Relating to the structural evolution, it should be pointed out that the research field presents great cohesion, because the majorities of detected themes are included into a thematic area and originated in a related previous subperiod. Furthermore, the majority of these evolutions take part of a common thematic nexus. There are themes from the last period (e.g., Intensive Care Units, Ankle Injuries, and Psychometry) there were not included in any thematic area. In theses cases, they could be considered as emergent new thematic areas. Thematic areas are composed of themes that clearly reflect their topic. Generally, the thematic areas present a structural growing pattern.

According to the performance values, some findings should be remarked. The thematic area Middle-Aged People is the most important topic with reference to the number of documents and citations, obtaining the highest-impact index and h-index. On the other hand, in second position, Muscle Function Alterations and Recovery is the thematic area with higher performance values. The thematic areas Health Education and Gait and Equilibrium also present a high citation value and h-index. All thematic areas present a growing trend in the number of documents published.

\section{DISCUSSION}

The present study describes the structure of the Physical Therapy research field based on its conceptual evolution. The conceptual themes and thematic areas of this research field have been visualized using papers published in WoS and Scopus.

Nine thematic areas have been identified in the Physical Therapy research field. Among these, there is one, focused on diseases and health aspects in relation to middle-aged people, very important in the development of Physical Therapy research field. This thematic area achieves the highest performance values. Its appearance is related to Simon et al. (2014) conclusions: "the main participants in Journal of Manual \& Manipulative Therapy studies were young to middle-aged symptomatic adults with low back and/or neck pain." The importance of muscle function, diseases, and anatomical aspects is high; their performance values are good, especially the thematic area focused on muscle contraction aspects. On the other hand, it should be pointed out the relation between gait and equilibrium, at the beginning the research is more centered in biomechanical aspects of gait and it has evolved to equilibrium. It seems to keep growing in that way, the theme equilibrium is becoming important in Physical Therapy research. The thematic area Health Education has an important theme called Education; it starts as a motor theme and presents high performance values. Throughout time span the theme Education is decreasing in scientific production and impact, it is more important in first years when the Physical Therapy curricula were developing. This fact is supported by Coronado et al. (2011) conclusions. Nevertheless, it is evident the current interest on educational aspects (Lopes et al., 2016; O’Connor et al., 2017). Otherwise, we can see how the Physical Therapy research field is becoming more specific in other thematic area as Heart Rate and Exercise. First, it is composed of themes such as Heart or Heart Rate, but in the last period, it is focused on Exercise. The thematic area Diagnosis at the beginning is more focused on diagnosis aspects, but they become less frequent in recent publications. Last, it is interesting to highlight the theme Low Back Pain,which seems to be a growing thematic area with a growing pattern in the future. The presence of these themes is also related to those topics suggested by Simon et al. (2014).

The thematic area Middle-Aged People reaches the best impact values with reference to the number of citations and h-index. This suggests that the importance of Physical Therapy in this population group is capturing the attention of the Physical Therapy research field. This finding is interesting and could be related to the concept of quality of life. The thematic area Muscle Function Alterations and Recovery is another highly developed thematic area with a high amount of documents. The number of documents published and the relation to different issues suggest that anatomical aspects and different injuries related to muscles are a major focus in this field. Overall, all thematic areas show a consistent development along the period studied. There has been an increment of the citations categorized in these thematic areas in the last period, indicating that there is a growing research interest in them.

Nevertheless, some study limitations can be highlighted. First, the use of WoS and Scopus as bibliographic sources implies that articles not indexed in the database have not been analyzed. 


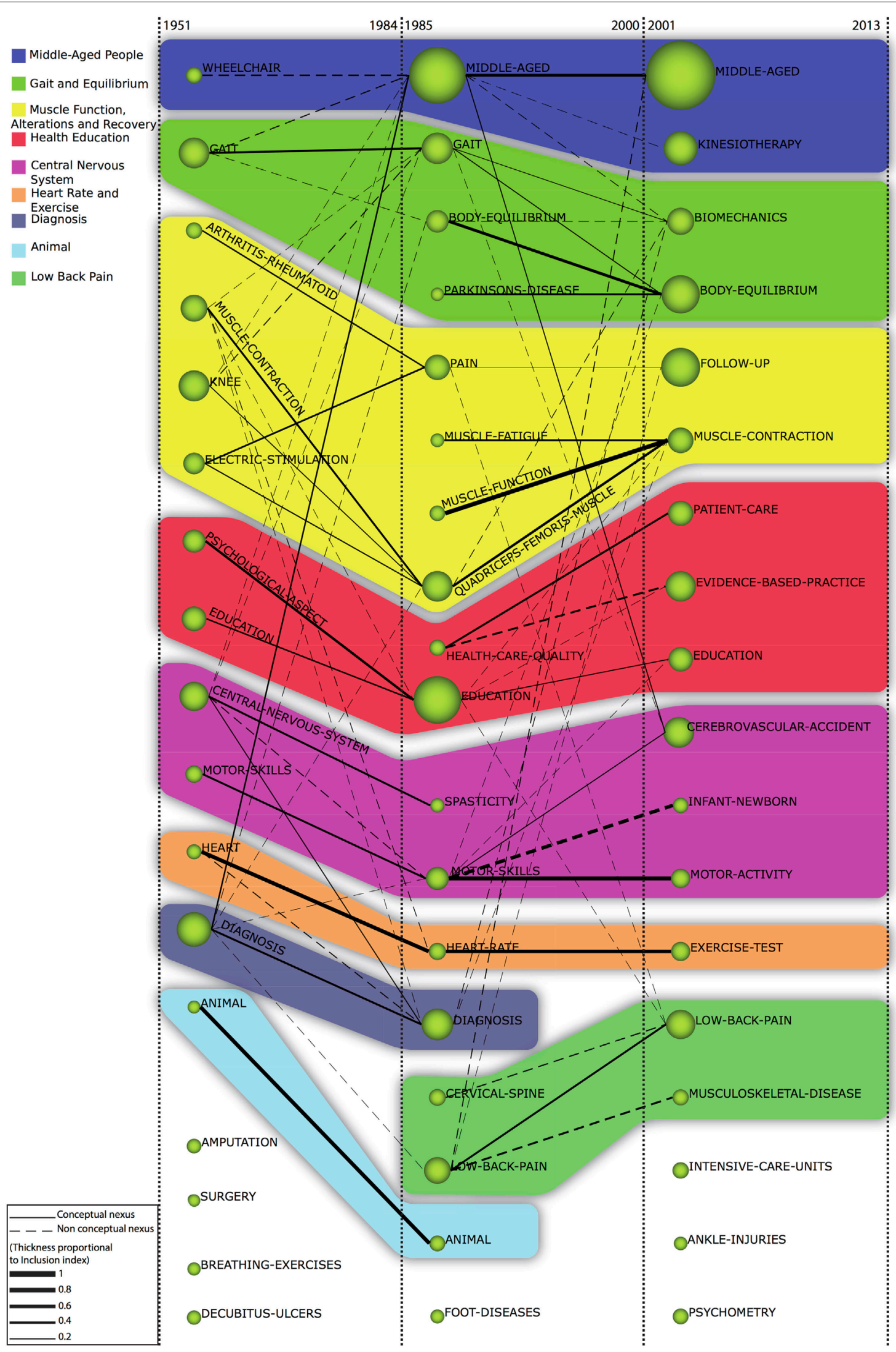

FIGURE 6 | Thematic evolution of Physiotherapy (1951-2013). 
Second, the journals selection was performed by choosing the most important among the professionals. Some important publications could have been excluded. If they would be taken into account, the detected thematic areas could change.

\section{CONCLUSION}

In relation to the study results, some conclusions can be made. The scientific community can now identify the interest focused, over time and trend, on the different thematic areas. It can be concluded that the Physical Therapy citations and production are primarily focused on two large thematic areas, diseases that involve middle-aged population and muscle function and its alterations. On the other hand, other thematic areas are important in terms of research interest. These include gait and equilibrium, health education, and central nervous system. Results show the fast growing of this research field and they suggest that it will follow attracting more research in the future. The findings reported

\section{REFERENCES}

Alonso, S., Cabrerizo, F. J., Herrera-Viedma, E., and Herrera, F. (2009). $\mathrm{H}$-index: a review focused in its variants, computation and standardization for different scientific fields. J. Infometrics 3, 273-289. doi:10.1016/j. joi.2009.04.001

Bandy, W. D., Irion, J. M., and Briggler, M. (1997). The effect of time and frequency of static stretching on flexibility of the hamstring muscles. Phys. Ther. 77, 1090-1096. doi:10.1093/ptj/77.10.1090

Berney, S., and Denehy, L. (2003). The effect of physiotherapy treatment on oxygen consumption and haemodynamics in patients who are critically ill. Aust. J. Physiother. 49, 99-105. doi:10.1016/S0004-9514(14)60126-4

Blum, L., and Korner-Bitensky, N. (2008). Usefulness of the berg balance scale in stroke rehabilitation: a systematic review. Phys. Ther. 88, 559-566. doi:10.2522/ ptj.20070205

Boone, D. C., Azen, S. P., Lin, C. M., Spence, C., Baron, C., and Lee, L. (1978). Reliability of goniometric measurements. Phys. Ther. 58, 1355-1360. doi:10.1093/ptj/58.11.1355

Börner, K., Chen, C., and Boyack, K. W. (2003). Visualizing knowledge domains. Annu. Rev. Inf. Sci. Technol. 37, 179-255. doi:10.1002/aris.1440370106

Callon, M., Courtial, J. P., and Laville, F. (1991). Co-word analysis as a tool for describing the network of interactions between basic and technological research: the case of polymer chemistry. Scientometrics 22, 155-205. doi:10.1007/ BF02019280

Callon, M., Courtial, J. P., Turner, W. A., and Bauin, S. (1983). From translations to problematic networks: an introduction to co-word analysis. Soc. Sci. Inf. 22, 191-235. doi:10.1177/053901883022002003

Chien, C.-L., Lee, C.-M., Wu, Y.-W., Chen, T.-A., and Wu, Y.-T. (2008). Home-based exercise increases exercise capacity but not quality of life in people with chronic heart failure: a systematic review. Aust. J. Physiother. 54, 87-93. doi:10.1016/ S0004-9514(08)70041-2

Chinchilla-Rodríguez, Z., Ocaña-Rosa, K., and Vargas-Quesada, B. (2016). How to combine research guarantor and collaboration patterns to measure scientific performance of countries in scientific fields: nanoscience and nanotechnology as a case study. Front. Res. Metrics Anal. 1, 2. doi:10.3389/frma.2016.00002

Cleland, J. A., Childs, J. D., Fritz, J. M., Whitman, J. M., and Eberhart, S. L. (2007). Development of a clinical prediction rule for guiding treatment of a subgroup of patients with neck pain: use of thoracic spine manipulation, exercise, and patient education. Phys. Ther. 87, 9-23. doi:10.2522/ptj.20060155

Cobo, M. J., López-Herrera, A. G., Herrera-Viedma, E., and Herrera, F. (2011a). An approach for detecting, quantifying, and visualizing the evolution of a research field: a practical application to the fuzzy sets theory field. J. Infometrics 5, 146-166. doi:10.1016/j.joi.2010.10.002

Cobo, M. J., López-Herrera, A. G., Herrera-Viedma, E., and Herrera, F. (2011b). Science mapping software tools: review, analysis, and cooperative study among tools. J. Assoc. Inf. Sci. Technol. 62, 1382-1402. doi:10.1002/asi.21525 in this study could be used to provide a historical framework of the research conducted in this field and an evidence-based model on which future research can be built.

\section{AUTHOR CONTRIBUTIONS}

JM-M is responsible for idea, concept, data retrieval, and data interpretation. $\mathrm{MC}$ is responsible for supervision of an adequate methodology application and data representation. MA-M and $\mathrm{EH}-\mathrm{V}$ are responsible for idea and final interpretation decisions.

\section{FUNDING}

This work was supported by FEDER funds (TIN2013-40658-P and TIN2016-75850-R). In addition to the financial support from the University of Cadiz Project (PR2016-067). JA M-M holds an FPU scholarship (AP2012-1789) from the Spanish Ministry of Education.

Cobo, M. J. J., López-Herrera, A. G. G., Herrera-Viedma, E., and Herrera, F. (2012) SciMAT: a new science mapping analysis software tool. J. Am. Soc. Inf. Sci. Technol. 63, 1609-1630. doi:10.1002/asi.22688

Coronado, R. A., Riddle, D. L., Wurtzel, W. A., and George, S. Z. (2011). Bibliometric analysis of articles published from 1980 to 2009 in physical therapy, journal of the American Physical Therapy Association. Phys. Ther. 91, 642-655. doi:10.2522/ptj.20100267

Coulter, N., Monarch, I., and Konda, S. (1998). Software engineering as seen through its research literature: a study in co-word analysis. J. Am. Soc. Inf. Sci. 49, 1206 1223. doi:10.1002/(SICI)1097-4571(1998)49:13<1206::AID-ASI7>3.0.CO;2-F

Dull, J. L., and Dull, W. L. (1983). Are maximal inspiratory breathing exercises or incentive spirometry better than early mobilization after cardiopulmonary bypass? Phys. Ther. 63, 655-659. doi:10.1093/ptj/63.5.655

Duncan, P. W., Propst, M., and Nelson, S. G. (1983). Reliability of the Fugl-Meyer assessment of sensorimotor recovery following cerebrovascular accident. Phys. Ther. 63, 1606-1610. doi:10.1093/ptj/63.10.1606

Emery, M. J. (1984). Effectiveness of the clinical instructor. Students' perspective. Phys. Ther. 64, 1079-1083. doi:10.1093/ptj/64.7.1079

Folpp, H., Deall, S., Harvey, L. A., and Gwinn, T. (2006). Can apparent increases in muscle extensibility with regular stretch be explained by changes in tolerance to stretch? Aust. J. Physiother. 52, 45-50. doi:10.1016/ S0004-9514(06)70061-7

French, H. P., and Dowds, J. (2008). An overview of continuing professional development in physiotherapy. Physiotherapy 94, 190-197. doi:10.1016/j. physio.2007.09.004

Gajdosik, R., and Lusin, G. (1983). Hamstring muscle tightness. Reliability of an active-knee-extension test. Phys. Ther. 63, 1085-1090. doi:10.1093/ptj/63.7.1085

García-Ríos, M. C., Moreno Lorenzo, C., Ruiz Baños, R., and Bailón Moreno, R. (2010). Thematic analysis of the discipline of physiotherapy in the web of science. Fisioterapia 32, 159-164. doi:10.1016/j.ft.2009.09.004

Gossman, M. R., Sahrmann, S. A., and Rose, S. J. (1982). Review of length-associated changes in muscle. Experimental evidence and clinical implications. Phys. Ther. 62, 1799-1808. doi:10.1093/ptj/62.12.1799

Gutiérrez-Salcedo, M., Martínez, M. Á, Moral-Munoz, J. A., Herrera-Viedma, E., and Cobo, M. J. (2017). Some bibliometric procedures for analyzing and evaluating research fields. Appl. Intell. 1-13. doi:10.1007/s10489-017-1105-y

Hirsch, J. (2005). An index to quantify an individual's scientific research output. Proc. Natl. Acad. Sci. U.S.A. 102, 16569-16572. doi:10.1073/pnas.0507655102

Hogeweg, J. A., Kuis, W., Oostendorp, R. A. B., and Helders, P. J. M. (1996). The influence of site of stimulation, age, and gender on pain threshold in healthy children. Phys. Ther. 76, 1331-1339. doi:10.1093/ptj/76.12.1331

Holden, M. K., Gill, K. M., Magliozzi, M. R., Nathan, J., and Piehl-Baker, L. (1984). Clinical gait assessment in the neurologically impaired. Reliability and meaningfulness. Phys. Ther. 64, 35-40. doi:10.1093/ptj/64.1.35

Jevsevar, D. S., Riley, P. O., Hodge, W. A., and Krebs, D. E. (1993). Knee kinematics and kinetics during locomotor activities of daily living in subjects with knee 
arthroplasty and in healthy control subjects. Phys. Ther. 73, 229-39; discussion 240-2. doi:10.1093/ptj/73.4.229

Lindstrom, I., Ohlund, C., Eek, C., Wallin, L., Peterson, L. E., Fordyce, W. E., et al. (1992). The effect of graded activity on patients with subacute low back pain: a randomized prospective clinical study with an operant-conditioning behavioral approach. Phys. Ther. 72, 273-279. doi:10.1093/ptj/72.4.279

Lopes, A. A., Almeida, P., and Lopes, A. F. (2016). Trends in physiotherapy education - retrospective analysis of ECPE congress abstracts. Physiotherapy 102, e258-e259. doi:10.1016/j.physio.2016.10.325

Lord, S., and Castell, S. (1994). Effect of exercise on balance, strength and reaction time in older people. Aust. J. Physiother. 40, 83-88. doi:10.1016/ S0004-9514(14)60454-2

Malouin, F., Potvin, M., Prevost, J., Richards, C. L., and Wood-Dauphinee, S. (1992). Use of an intensive task-oriented gait training program in a series of patients with acute cerebrovascular accidents. Phys. Ther. 72, 781-9; discussion 789-93. doi:10.1093/ptj/72.11.781

Martínez-Fuentes, J. (2014). Base intelectual de la fisioterapia a través del análisis de cocitación de documentos (1983-2009). [dissertation]. Universidad Católica San Antonio de Murcia, Murcia, Spain.

Martínez-Fuentes, J., Ríos-Díaz, J., Meroño-Gallut, A. J., Martínez-Payá, J. J., and Del-Baño-Aledo, M. E. (2014). Characterization of the intellectual basis of physiotherapy through the co-citation analysis of documents. Fisioterapia 36, 167-176. doi:10.1016/j.ft.2013.10.001

Massey, B. F. (2001). 2001 APTA presidential address: we have arrived! Phys. Ther. 81, 1830-1833. doi:10.1093/ptj/81.11.1830

Massey, B. F. (2003). 2003 APTA presidential address-making vision 2020 a reality. Phys. Ther. 83, 1017-1021.

Moral-Munoz, J.A., Cobo, M. J., Peis, E., Arroyo-Morales, M., and HerreraViedma, E. (2014). Analyzing the research in integrative \& complementary medicine by means of science mapping. Complement. Ther. Med. 22, 409-418. doi:10.1016/j.ctim.2014.02.003

Morris, S., and Van Der Veer Martens, B. (2008). Mapping research specialities. Annu. Rev. Inf. Sci. Technol. 42, 213-295. doi:10.1002/aris.2008.1440420113

Murray, M. P., Gardner, G. M., Mollinger, L. A., and Sepic, S. B. (1980). Strength of isometric and isokinetic contractions: knee muscles of men aged 20 to 86 . Phys. Ther. 60, 412-419. doi:10.1093/ptj/60.4.412

Noyons, E. C. M., Moed, H. F., and Luwel, M. (1999). Combining mapping and citation analysis for evaluative bibliometric purposes: a bibliometric study. J. Am. Soc. Inf. Sci. 50, 115-131. doi:10.1002/(SICI) 1097-4571(1999)50:2<115::AID-ASI3>3.0.CO;2-J

O'Connor, A., McGarr, O., Cantillon, P., McCurtin, A., and Clifford, A. (2017). Clinical performance assessment tools in physiotherapy practice education: a systematic review. Physiotherapy 104, 46-53. doi:10.1016/j.physio.2017.01.005

Rothstein, J. M., Miller, P. J., and Roettger, R. F. (1983). Goniometric reliability in a clinical setting. Elbow and knee measurements. Phys. Ther. 63, 1611-1615. doi:10.1093/ptj/63.10.1611

Saragiotto, B. T., Costa, L., Oliveira, R. F., Lopes, A. D., Moseley, A. M., and Costa, L. O. P. (2014). Description of research design of articles published in four Brazilian physical therapy journals. Braz. J. Phys. Ther. 18, 56-62. doi:10.1590/ S1413-35552012005000136

Short, M. A., DiCarlo, S., Steffee, W. P., and Pavlou, K. (1984). Effects of physical conditioning of self-concept of adult obese males. Phys. Ther. 64, 194-198. doi:10.1093/ptj/64.2.194
Shumway-Cook, A., Baldwin, M., Polissar, N. L., and Gruber, W. (1997). Predicting the probability for falls in community-dwelling older adults. Phys. Ther. 77, 812-819. doi:10.1093/ptj/77.8.812

Simon, C. B., Coronado, R. A., Wurtzel, W. A., Riddle, D. L., and George, S. Z. (2014). Content and bibliometric analyses of the journal of manual \& manipulative therapy. J. Man. Manip. Ther. 22, 181-190. doi:10.1179/2042618614Y. 0000000075

Small, H. (1999). Visualizing science by citation mapping. J. Am. Soc. Inf. Sci. 50, 799-813.doi:10.1002/(SICI)1097-4571(1999)50:9<799::AID-ASI9>3.0.CO;2-G

Smidt, N., de Vet, H. C. W., Bouter, L. M., Dekker, J., Arendzen, J.H., de Bie, R. A., et al. (2005). Effectiveness of exercise therapy: a best-evidence summary of systematic reviews. Aust. J. Physiother. 51, 71-85. doi:10.1016/ S0004-9514(05)70036-2

Snyder-Mackler, L., Delitto, A., Stralka, S. W., and Bailey, S. L. (1994). Use of electrical stimulation to enhance recovery of quadriceps femoris muscle force production in patients following anterior cruciate ligament reconstruction. Phys. Ther. 74, 901-907. doi:10.1093/ptj/74.10.901

Tilson, J. K., Marshall, K., Tam, J. J., and Fetters, L. (2016). A bibliometric analysis of statistical terms used in American Physical Therapy Association journals (2011-2012): evidence for educating physical therapists. BMC Med. Educ. 16:118. doi:10.1186/s12909-016-0641-1

van Leeuwen, T. N., and Wouters, P. F. (2017). Analysis of publications on journal impact factor over time. Front. Res. Metrics Anal. 2:4. doi:10.3389/ frma.2017.00004

van Raan, A. F. J. (2005). Measuring Science in Handbook of Quantitative Science and Technology Research, eds H. F. Moed, W. Glänzel, and U. Schmoch (Netherlands: Springer), 19-50.

Vargas-Quesada, B., Chinchilla-Rodríguez, Z., and Rodríguez, N. (2017). Identification and visualization of the intellectual structure in graphene research. Front. Res. Metrics Anal. 2:7. doi:10.3389/frma.2017.00007

Vernaza-Pinzón, P., and Álvarez-Bravo, G. (2011). Latin American scientific output in physical therapy/kinesiology. Aquichán 11, 94-107. doi:10.5294/ aqui.2011.11.1.7

Wakiji, E. M. (1997). Mapping the literature of physical therapy. Bull. Med. Libr. Assoc. 85, 284-288.

Wiles, L., Matricciani, L., Williams, M., and Olds, T. (2012). Sixty-five years of physical therapy: bibliometric analysis of research publications from 1945 through 2010. Phys. Ther. 92, 493-506. doi:10.2522/ptj.20110013

Winter, D. A., Patla, A. E., Frank, J. S., and Walt, S. E. (1990). Biomechanical walking pattern changes in the fit and healthy elderly. Phys. Ther. 70, 340-347. doi:10.1093/ptj/70.6.340

Conflict of Interest Statement: The authors declare that the research was conducted in the absence of any commercial or financial relationships that could be construed as a potential conflict of interest.

Copyright (c) 2018 Moral-Munoz, Arroyo-Morales, Herrera-Viedma and Cobo. This is an open-access article distributed under the terms of the Creative Commons Attribution License (CC BY). The use, distribution or reproduction in other forums is permitted, provided the original author(s) and the copyright owner are credited and that the original publication in this journal is cited, in accordance with accepted academic practice. No use, distribution or reproduction is permitted which does not comply with these terms. 